\title{
Protective effect of curcumin against cyclosporine A-induced rat nephrotoxicity
}

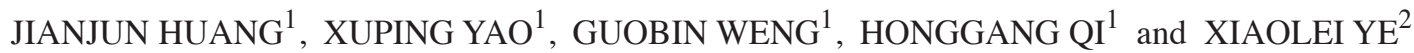 \\ ${ }^{1}$ Department of Urology, Ningbo Urology and Nephrology Hospital; \\ ${ }^{2}$ Ningbo Institute of Medical Sciences, Ningbo University, Ningbo, Zhejiang 315100, P.R. China
}

Received May 14, 2017; Accepted November 2, 2017

DOI: $10.3892 / \mathrm{mmr} .2018 .8591$

\begin{abstract}
This study explored the potential value of curcumin, a natural product, in the protection of CsA-induced nephrotoxicity. The aim of the present study was to investigate the effects of curcumin on Cyclosporine A (CsA)-induced renal oxidative stress and determine the potential underlying molecular mechanisms of the renal protective effects of Cur. HK-2 human renal cells were co-treated with $\mathrm{CsA}$ and various doses of Cur. Cell survival rate was determined by an MTT assay, total cellular protein was collected and oxidative stress in cell homogenates was evaluated by determining the activity of superoxide dismutase (SOD), glutathione peroxidase (GSH-Px) and catalase (CAT), the levels of malondialdehyde (MDA) and reactive oxygen species (ROS), and total antioxidant capacity. Furthermore, Bcl-2 and Bcl-2-associated X (Bax) protein expression was measured by western blot analysis. In addition, a CsA-induced nephrotoxicity (CAN) rat model was also established. Renal function was analyzed by measuring creatinine (Crea) and blood urea nitrogen (BUN) in the serum of rats, and histopathological examination was performed on renal tissues using hematoxylin and eosin staining, periodic acid-Schiff staining and nuclear factor- $\kappa \mathrm{B}(\mathrm{NF}-\kappa \mathrm{B})$ immunostaining. The results demonstrated that treatment of $\mathrm{HK}-2$ cells with CsA significantly increased ROS and MDA levels, and decreased the activities of SOD, GSH-Px and CAT, compared with the control group. However, these effects of CsA were dose-dependently improved by treatment with Cur. In addition, Cur treatment increased Bcl-2 and decreased Bax protein in $\mathrm{HK}-2$ cells, compared with cells treated with CsA alone. In the CAN rat model CsA $(30 \mathrm{mg} / \mathrm{kg})$ treatment significantly elevated serum Crea levels and BUN, but lowered endogenous Crea clearance rate, compared with the control group.
\end{abstract}

Correspondence to: Professor Guobin Weng or Dr Honggang Qi, Department of Urology, Ningbo Urology and Nephrology Hospital, Ningbo University, 1 Qianhe Road, Ningbo, Zhejiang 315100, P.R. China

E-mail: ddwgb@aliyun.com

E-mail: qi_honggang@163.com

Key words: curcumin, cyclosporine A, renal oxidative stress
Co-administration of Cur with CsA significantly reversed the effects of CsA on serum Crea levels, BUN and Crea clearance rate (Ccr). Additionally, Cur alleviated CsA-induced renal cell injury, as less vacuolar degeneration of glomerular cells was observed compared with the CsA alone group. In conclusion, Cur may increase renal antioxidant capacity and reduce the $\mathrm{Bax} / \mathrm{Bcl}-2$ ratio, subsequently improving CsA-induced renal failure and renal tubular deformation and cell vacuolization.

\section{Introduction}

Conventional use of cyclosporine A ( $\mathrm{CsA}$ ) following kidney transplantation is considered to be associated with the development of chronic allograft nephropathy, which leads to a gradual and irreversible loss of graft function and is a major cause of redialysis following renal transplantation (1). At present, the mechanism of CsA-induced nephrotoxicity (CAN) is not fully understood, however, results indicate that CsA may lead to an increase in reactive oxidative metabolites and reduced renal antioxidant capacity (2). Oxidative stress is a major trigger of CAN. CsA directly induces endothelial cell membrane lipid peroxidation and oxidative stress in cells, which enhances the production of oxygen free radicals $(3,4)$. In addition, CsA also blocks the formation of nitric oxide, thereby increasing the damage caused by oxidative stress. Blocking the expression of nuclear factor- $\kappa \mathrm{B}(\mathrm{NF}-\kappa \mathrm{B})$ reduces the production of reactive oxidative metabolites and improves kidney antioxidant capacity $(5,6)$. Curcumin (Cur) has been reported to increase the proliferation, reduce the rate of apoptosis and reduce the $\mathrm{Bcl}-2$-associated $\mathrm{X}(\mathrm{Bax}) / \mathrm{Bcl}-2$ ratio in human umbilical vein endothelial cells (7).

Oxidative stress is also associated with the occurrence of CAN (8). Histological manifestations of CAN include progressive glomerulosclerosis, interstitial fibrosis associated with mononuclear cell infiltration and renal tubular atrophy, while the primary clinical manifestations are progressive deterioration of renal function, hypertension and proteinuria $(9,10)$. These manifestations are consistent with renal injury in which oxidative stress is the major cause. There is also evidence that oxidative stress is involved in the glomerular atrophy observed in interstitial fibrosis of epithelial cells to fibroblasts during the process of metaplasia (11). Oxidative stress in chronic graft kidney glomerular atrophy interstitial degeneration in an animal experimental model has also been confirmed (12), increased 
cell membrane unsaturated fatty acids and cholesterol lipid peroxidation was observed, while the cell membrane fluidity was decreased and permeability was increased, affecting the membrane-associated enzyme involved in the biochemical process and ion pump function. In addition, oxidative stress may also induce the oxidation of biological macromolecules, and protein structure and conformational were altered through the direct effect on the sensitive amino acids (tryptophan, tyrosine, histidine and cysteine), or through lipid peroxidation products causing oxidative damage, leading to cell death or apoptosis, tissue and organ damage (13). Oxidative stress also leads to the dysfunction of important intracellular organelles, such as the mitochondrial inner membrane that functions in the oxidative phosphorylation process, which leads to mitochondrial dysfunction $(14,15)$. Studies have demonstrated that oxidative stress is also an important intracellular messenger, activating various intracellular signaling pathways $(16,17)$ and mediating cell stress responses and injury responses. Oxidative stress is an important pathogenic factor influencing the recovery of short- and long-term function following renal transplantation (18-20). The progression of CAN may be alleviated according to the characteristics of its different stages and the application of suitable antioxidants.

Cur is a yellow, acidic phenol that is extracted from Curcuma longa L., also termed Turmeric, is one member of ginger family (21). Cur is the major active ingredient that has a pharmacological role. Cur is a type of plant polyphenol that exhibits a wide range of biological activities, including antioxidative, anti-inflammatory, anticancer, anti-atherosclerotic, antimutagenic and immunoregulatory effects (22). Cur has antioxidant capacity in neutral and acidic environments, and interferes with cell signaling at various levels and affects biological enzyme activity, angiogenesis and cell adhesion $(23,24)$. It was also reported in a preclinical study that Cur influences gene transcription and induces apoptosis (25). In rat kidneys, Cur alleviates damage caused by nephrotoxic substances, including doxorubicin, cyclosporine, gentamicin, chloroquine and ischemia-reperfusion injury due to its antioxidant properties (26-28). The potential of Cur in the prevention and treatment of diabetic nephropathy is primarily based on its antioxidative $(29,30)$ and antifibrotic (31) properties; to the best of our knowledge, its role in inflammatory lesions has not previously been reported. Cur is reported to inhibit the activity of lipoxygenase and cyclooxygenase (32), reduce free radicals generated from the arachidonic acid pathway, suppress xanthine oxidase activity (33), decrease adenosine metabolism of free radicals and interfere with nitric oxide synthase activity (34) to reduce the arginine metabolism of nitric oxide caused by the generation of free radicals, thereby limiting oxygen free radical damage and exhibiting a protective role. Cur may function in the antioxidant process through various mechanisms $(35,36)$ : Cur and its derivatives inhibit metal ion $\left(\mathrm{Fe}^{2+}\right.$ and $\left.\mathrm{Cu}^{2+}\right)$-induced lipid peroxidation, inhibits oxidative modification of low density lipoprotein and protects DNA from oxidative lipid damage; Cur inhibits the production of reactive oxygen species and scavenging free radicals (including $\cdot \mathrm{OH}, \mathrm{DPPH} \cdot$ and $\mathrm{O}^{-}$) and peroxide. Cur reduces serum and tissue lipid peroxide levels and enhances superoxide dismutase (SOD) and glutathione peroxidase (GSH-Px) activity; Cur inhibits NADPH oxidase expression and the activation of xanthine oxidase 8; and Cur inhibits the synthesis of nitric oxide or accelerates its clearance so that levels in the kidney are low to prevent nitric oxide toxicity. The effect of oxidative stress on chronic CsA renal injury in rats and the effect of Cur on renal injury have not been widely reported. Therefore, the present study aimed to provide an experimental basis for the further development and application of the natural active substance, Cur.

\section{Materials and methods}

Drugs. Cur, with a purity of $99.8 \%$, was purchased from Shijiazhuang spring letter Biotechnology Co., Ltd. (Shijiazhuang, China; http://www.sjzcxswkj.com) and CsA was obtained from Zhejiang Ruibang Pharmaceutical Co., Ltd. (Wenzhou, China).

Primary reagents. Rabbit anti-human Bax primary antibody and horseradish peroxidase-conjugated goat anti-rabbit secondary antibody were purchased from Cell Signaling Technology, Inc. (Danvers, MA, USA). Rabbit anti-human Bcl-2 primary antibody and $\beta$-actin primary antibody were purchased from Abcam (Cambridge, UK). SOD (cat no. A001-3), malondialdehyde (MDA; cat no. A003-1), GSH-Px (cat no. A005), reactive oxygen species (ROS; cat no. E004) and catalase (CAT; cat no. A007-1-1) detection kits were all purchased from Nanjing Jiancheng Bioengineering Institute (Nanjing, China). Other reagents were of domestic and analytical grade.

HK-2 human renal cells culture. HK-2 cells were purchased from Beijing Zhongyuan Jinqiao Biotechnology Co., Ltd. (Beijing, China). The base medium for this cell line was provided by Invitrogen; Thermo Fisher Scientific, Inc. (Waltham, MA, USA) as part of a kit: Keratinocyte serum free medium (K-SFM; kit cat no. 17005-042). This kit was supplied with each of the two additives required to grow this cell line (bovine pituitary extract (BPE) and human recombinant epidermal growth factor (EGF). The following components were added the base medium: $0.05 \mathrm{mg} / \mathrm{ml}$ BPE-provided with the K-SFM kit; $5 \mathrm{ng} / \mathrm{ml}$ EGF-provided with the K-SFM kit. Atmosphere: air, 95\%; carbon dioxide $\left(\mathrm{CO}_{2}\right), 5 \%, 37.0^{\circ} \mathrm{C}$ and humidity $70-80 \%$.

Detection of oxidative stress in HK-2 human renal cells. HK-2 cells $\left(2 \times 10^{4}\right.$ cells/well) were assigned to the following groups for $48 \mathrm{~h}$ at $37^{\circ} \mathrm{C}$ in a $5 \% \mathrm{CO}_{2}$ incubator: Control (equivalent volume of saline), $50 \mu \mathrm{M}$ Cur, $2 \mu \mathrm{M}$ CsA, $10 \mu \mathrm{M}$ Cur $+2 \mu \mathrm{M}$ CsA, $50 \mu \mathrm{M}$ Cur $+2 \mu \mathrm{M}$ CsA, $100 \mu \mathrm{M} \mathrm{Cur}+2 \mu \mathrm{M}$ CsA and $5 \mu \mathrm{M}$ N-acetyl-L-cysteine (NAC; Sigma-Aldrich; Merck KGaA, Darmstadt, Germany). Cells were washed with PBS, collected in a test tube with $1 \mathrm{ml}$ normal saline and lysed with an ultrasonic crusher. After centrifugation at 12,000 x g for $10 \mathrm{~min}$ at $4^{\circ} \mathrm{C}$, SOD activity and MDA levels in the supernatant were measured by SOD and MDA kits, a GSH-Px detection kit was used to measure GSH-Px activity, an ROS detection kit was used to measure ROS levels and a CAT detection kit was used to determine CAT activity.

MTT assay. HK-2 cells in logarithmic growth phase were inoculated in 96 -well plates $\left(5 \times 10^{3}\right.$ cells per well), added with 
different concentrations of $\operatorname{Cur}(0.1,1,10,100$ and 1,000 $\mu \mathrm{M})$ and then co-incubated with or without $(2 \mu \mathrm{M})$ for $24 \mathrm{~h}$ at $37^{\circ} \mathrm{C}$. After incubating at $37^{\circ} \mathrm{C}$ for $4 \mathrm{~h}$ with $20 \mu \mathrm{MTT}(5 \mathrm{mg} / \mathrm{ml})$, $200 \mu \mathrm{l}$ DMSO was added. After 10 min vibration, the absorbance value of the mixture was measured at $560 \mathrm{~nm}$ using a microplate reader.

Western blot analysis. HK-2 cells in the control and different treatment groups were washed three times with cold PBS and lysed with RIPA lysis buffer (Beyotime Institute of Biotechnology, Haimen, China; cat. no. P0013B) on ice. Lysates were collected and centrifuged at $12,000 \mathrm{x} \mathrm{g}$ for $10 \mathrm{~min}$ at $4^{\circ} \mathrm{C}$, the supernatants were collected and protein concentration was determined by a BCA assay. A 10\% SDS-PAGE gel was prepared and samples were loaded ( $80 \mu \mathrm{g}$ protein per lane), and run on the gel. After $2 \mathrm{~h}$ of SDS-PAGE, proteins were transferred to polyvinylidene difluoride membranes. Subsequently, blocking with 5\% non-fat milk was performed for $1 \mathrm{~h}$ at room temperature and the membranes were incubated with diluted primary antibodies, including rabbit anti-human Bax (cat. no. 5023; 1:1,500 dilution), anti- $\beta$ actin antibody (cat no. ab227387; 1:2,000 dilution) and Bcl-2 (cat. no. ab194583; 1:2,000 dilution) antibodies overnight at $4^{\circ} \mathrm{C}$. The membrane was washed three times with $1 \mathrm{X}$ TBS $0.1 \%$ Tween-20 and then the horseradish peroxidase-conjugated goat anti-rabbit secondary antibody (cat. no. 7074; 1:4,000) was added and incubated with the membrane at room temperature for $2 \mathrm{~h}$. Grey scale and area of the protein band were analyzed by gel imaging system (Bio-Rad Laboratories, Inc., Hercules, CA, USA) with enhanced chemiluminescent kit (SuperSignal; Pierce, Thermo Fisher Scientific, Inc.; cat no. 34094). The protein expression level was indicated by the integral grey value ( $\mathrm{D}$, density) using Image $\mathbf{J}$ software (National Institutes of Health, USA).

Apoptosis assay. HK-2 cells treated with medium or different drugs for $48 \mathrm{~h}$ were collected and treated according to the Annexin V-FITC Apoptosis Detection kit (Vazyme Biotech; cat no. a211-01). After washing twice with PBS, cells were suspended with $1 \mathrm{X}$ binding buffer, added with $5 \mu \mathrm{l}$ of fluorescein isothiocyanate labeled Annexin V and $5 \mu \mathrm{l}$ of PI, and then mixed gently. After incubation at room temperature for $15 \mathrm{~min}$, the cells were analyzed by flow cytometry. A total of 20,000 cells were analyzed each time.

$C A N$ rats model. Male Sprague-Dawley rats $(\mathrm{n}=60 ; 7$ weeks of age), clean grade and weighing 200-250 g, were purchased from the Experimental Animal Center of Changzhou Cavens Laboratory Animal Co., Ltd. (Changzhou, China) and kept under controlled conditions (temperature $23 \pm 1.5^{\circ} \mathrm{C}$, relative humidity 40-60\%, 0.03-0.04\% $\mathrm{CO}_{2}, 12 / 12$ light/dark cycle)- at the Animal Center of Ningbo University (Ningbo, China). Rats were allowed free access to drinking water and food. The present study was approved by the animal ethical committee of the Medical School of Ningbo university. The rats were randomly divided into four groups according to their body weight, with $n=6$ per group: Control group, Cur group (30 mg/kg/day) (37)-, CsA group (20 mg/kg/day) and Cur (30 mg/kg/day) + CsA (20 mg/kg/day) group, all of which were administered for 21 days. The control group received $0.9 \%$
Table I. Effect of Cur on CsA-induced renal dysfunction in rats.

\begin{tabular}{lccc}
\hline Group & BUN, mmol/l & $\begin{array}{c}\text { Serum } \\
\text { Crea, } \mu \mathrm{mol} / \mathrm{l}\end{array}$ & Ccr, ml/min \\
\hline Cur & $4.77 \pm 0.52$ & $53.12 \pm 5.32$ & $0.22 \pm 0.08$ \\
CsA & $10.47 \pm 1.45^{\mathrm{c}}$ & $68.33 \pm 10.12^{\mathrm{b}}$ & $0.17 \pm 0.11^{\mathrm{a}}$ \\
Cur+CsA & $6.68 \pm 0.91^{\mathrm{b}, \mathrm{e}}$ & $57.98 \pm 8.96^{\mathrm{a}, \mathrm{d}}$ & $0.18 \pm 0.09^{\mathrm{d}}$ \\
Control & $4.88 \pm 0.71$ & $49.62 \pm 6.23$ & $0.22 \pm 0.06$ \\
\hline
\end{tabular}

${ }^{\mathrm{a}} \mathrm{P}<0.05,{ }^{\mathrm{b}} \mathrm{P}<0.01$ and ${ }^{\mathrm{c}} \mathrm{P}<0.001$ vs. control group; ${ }^{\mathrm{d}} \mathrm{P}<0.05$ and ${ }^{\mathrm{e}} \mathrm{P}<0.001$ vs. CsA alone group. $\mathrm{n}=6$ per group. Cur, curcumin; CsA, cyclosporine A; BUN, blood urea nitrogen; Crea, creatinine; Ccr, Crea clearance rate.

sodium chloride injection ( $4 \mathrm{ml} / \mathrm{kg} /$ day, intragastric) + vegetable oil ( $2 \mathrm{ml} / \mathrm{kg} /$ day, subcutaneous), the Cur group received Cur (30 mg/kg/day, intragastric) + vegetable oil $(2 \mathrm{ml} / \mathrm{kg} /$ day, subcutaneous), the CsA group received $0.9 \%$ sodium chloride injection (4 ml/ kg/day, intragastric) + CsA (20 mg/kg/day dissolved in vegetable oil, subcutaneous) and the $\mathrm{CsA}+\mathrm{Cur}$ group received Cur (30 mg/kg/day, intragastric) + CsA (20 mg/kg/day dissolved in vegetable oil, subcutaneous).

Renal function test. On the 22nd day, $24 \mathrm{~h}$ urine of rats was collected by a metabolic cage. The rats were anesthetized with ether and 3.0-4.0 $\mathrm{ml}$ blood was collected to obtain serum by centrifugation at $1,400 \times \mathrm{g}$ for $30 \mathrm{~min}$ at $4^{\circ} \mathrm{C}$. Serum/urine creatinine (Crea) and blood urea nitrogen (BUN) levels were measured with a Hitachi Model 7060 automatic biochemical analyzer, and creatinine clearance (Ccr) was calculated as follows: $\mathrm{Ccr}=[$ urine Crea concentration $\mathrm{x} 1 \mathrm{~h}$ urine volume $(\mathrm{ml})] /$ serum Crea concentration.

Histopathological examination. On the 22nd day, rat kidneys were fixed with $5 \%$ formaldehyde at $4^{\circ} \mathrm{C}$ for $48 \mathrm{~h}$ to prepare paraffin blocks and tissue sections $(5 \mu \mathrm{m})$ following dehydration. For histological investigation, the deparaffinized and rehydrated rat kidney tissue sections were stained with hematoxylin for $15 \mathrm{~min}$ and $1 \%$ eosin for $3 \mathrm{~min}$ at room temperature by the Hematoxylin and Eosin Staining kit (Beyotime Institute of Biotechnology; cat no. C0105). For periodic acid-Schiff (PAS) staining, the slides were immersed in periodic acid solution for $10 \mathrm{~min}$, and then immersed in Schiff's solution for $30 \mathrm{~min}$ at $20^{\circ} \mathrm{C}$ after being rinsed with distilled water 4 times using a Periodic Acid Schiff (PAS) Staining kit (cat no. ab150680). After rinsing slides under hot running tap water, the slides were stained with hematoxylin for $3 \mathrm{~min}$, rinsed in running tap water for $3 \mathrm{~min}$ and applied the bluing reagent for $30 \mathrm{sec}$. Finally, the distilled water rinsed slides were dehydrated through graded alcohols. Expression of $\mathrm{NF}-\kappa \mathrm{B}$ in kidney tissue was detected by immunohistochemistry. In brief, tissues in paraffin sections were treated with the following procedures, including dewaxing, incubation with anti-NF-kB p65 antibody (cat no. ab16502; 1:1,000 dilution) for overnight at $4^{\circ} \mathrm{C}$ and horse radish peroxidse-conjugated goat anti-rabbit secondary antibody (CST; cat no. 7074) for 
A
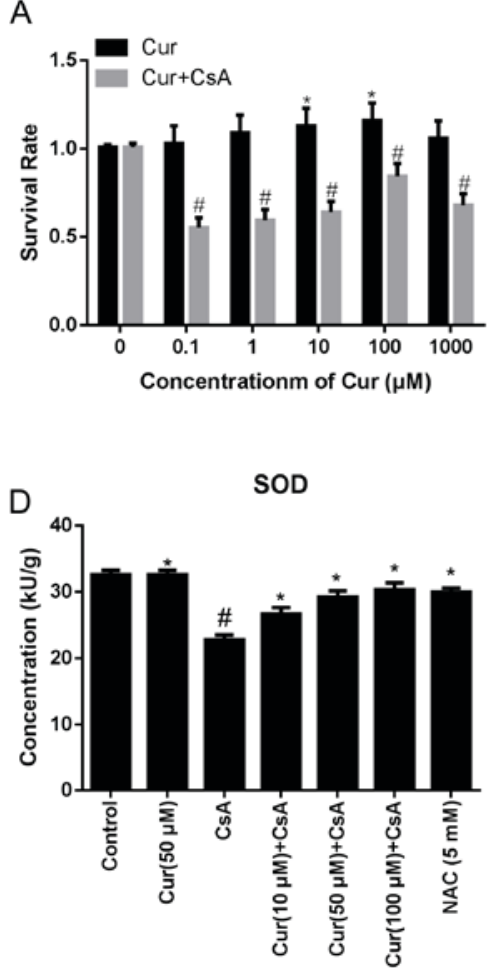
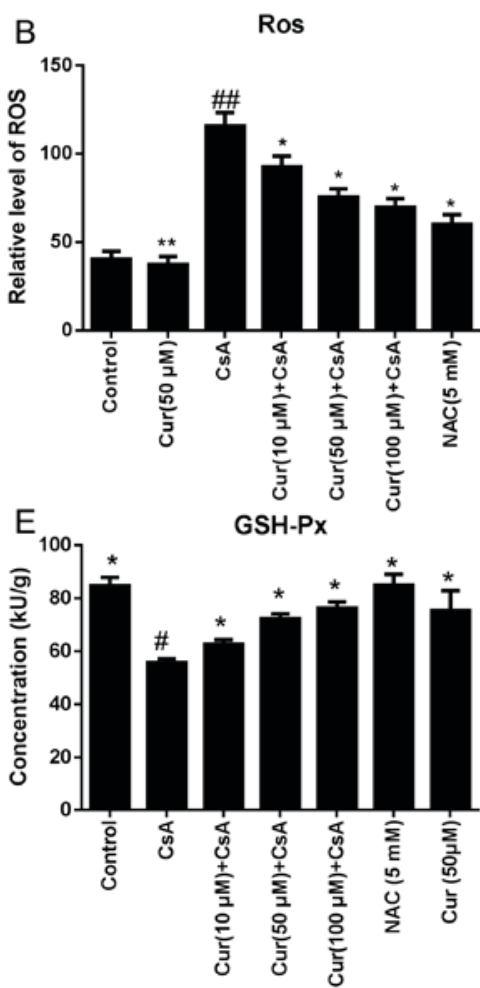

$\mathrm{C}$

MDA
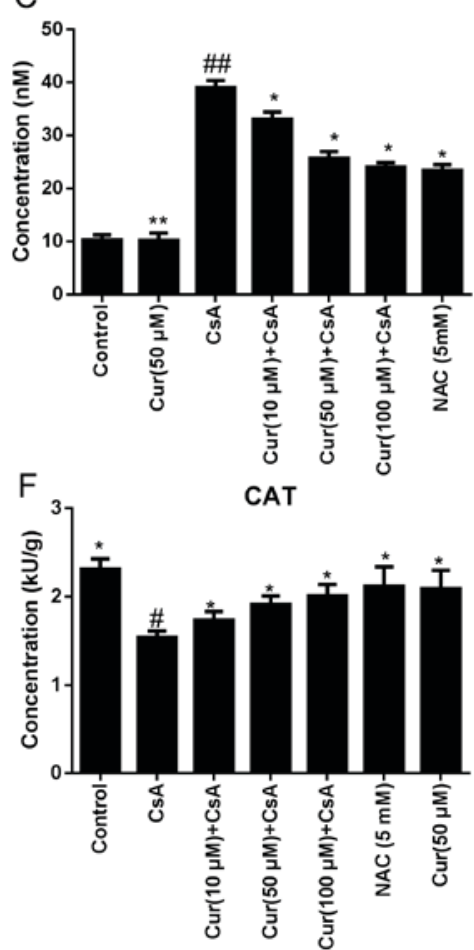

Figure 1. Effect of different concentrations of Cur on HK-2 cell viability, oxidative stress-associated factors and antioxidant enzyme activity. (A) An MTT assay was performed to determine the effect of Cur on the survival rate of HK-2 cells. (B) Effect of Cur on the production of ROS in HK-2 cells. (C) Effect of Cur on the production of MDA in HK-2 cells. (D) Effect of Cur on SOD activity in HK-2 cells. (E) Effect of Cur on the activity of GSH-Px in HK-2 cells. (F) Effect of Cur on the activity of CAT in HK-2 cells. ${ }^{~} \mathrm{P}<0.05$ and ${ }^{\# \#} \mathrm{P}<0.01$ vs. control cells; ${ }^{*} \mathrm{P}<0.05$ and ${ }^{* * *} \mathrm{P}<0.01$ vs. CsA only-treated cells. Cur, curcumin; ROS, reactive oxygen species; MDA, malondialdehyde; SOD, superoxide dismutase; GSH-Px, glutathione peroxidase; CAT, catalase; CsA, cyclosporine A; NAC, $\mathrm{N}$-acetylcysteine.

$2 \mathrm{~h}$ at room temperature, stained with DAB and mounted with anti-fade oil. All sections were observed at x200 magnification on a light microscope (37).

Statistical analysis. All statistical analyses were performed with PASW Statistics 18.0 software (SPSS, Inc., Somers, USA). Data are presented as the mean \pm standard deviation. One-way analysis of variance and the Tukey post-hoc test were used to analyze the significance between the groups. $\mathrm{P}<0.05$ was considered to indicate a statistically significant difference.

\section{Results}

Cur alleviates oxidative stress in CsA-treated HK-2 cells. In vitro, a concentration of $100 \mu \mathrm{M}$ Cur improved cell viability when treated with CsA, compared with lower concentrations of Cur (Fig. 1A). The levels of ROS and MDA were significantly downregulated in a dose-dependent manner following treatment with Cur, compared with the CsA alone group, as demonstrated in Fig. 1B and C. The ROS level in the CsA alone group was $115.67 \pm 7.66 \mathrm{KU} / \mathrm{g}$, while levels in the $100 \mu \mathrm{M}$ Cur + CsA group were $71.67 \pm 5.35 \mathrm{KU} / \mathrm{g}(\mathrm{P}<0.01$; Fig. 1B) MDA levels in the CsA alone group were 39.01 \pm 1.36 , while levels in the $100 \mu \mathrm{M}$ Cur + CsA group were $23.85 \pm 1.22 \mathrm{nM}$ $(\mathrm{P}<0.01$; Fig. 1C). In addition, the activity of SOD was increased in the $100 \mu \mathrm{M}$ Cur + CsA group $(22.76 \pm 0.73 \mathrm{KU} / \mathrm{g}$ in the CsA alone group vs. $32.6 \pm 0.66 \mathrm{KU} / \mathrm{g}$ in the $100 \mu \mathrm{M}$ Cur + CsA group; $\mathrm{P}<0.05$; Fig. 1D) and the GSH-Px activity was also increased following treatment with $100 \mu \mathrm{M}$ Cur $(55.65 \pm 1.45$ in the CsA alone group vs. $76.04 \pm 2.07 \mathrm{KU} / \mathrm{g}$ in the $100 \mu \mathrm{M}$ Cur + CsA group; $\mathrm{P}<0.05$; Fig. 1E). Furthermore, CAT activity was increased in the $100 \mu \mathrm{M}$ Cur-treated group compared with the CsA alone group $(1.54 \pm 0.07$ in the CsA alone group vs. $2.31 \pm 0.12 \mathrm{KU} / \mathrm{g}$ in the $100 \mu \mathrm{M} \mathrm{Cur}+\mathrm{CsA}$ group; $\mathrm{P}<0.05$; Fig. 1F). CsA-induced increases in ROS and MDA, and decreases in SOD, GSH-Px and CAT activity, were dose-dependently reversed by treatment with Cur (Fig. 1B-F).

Effects of Cur on Bax and Bcl-2 protein expression. The results in Fig. 2A demonstrate that the rate of apoptosis was gradually decreased with increasing concentrations of Cur in HK-2 cells, compared with the CsA alone group, which indicated that Cur may inhibit CsA-induced cell apoptosis. The ratio of Bax/Bcl-2 is an important indicator in the balance between cell apoptosis and survival. The ratio of $\mathrm{Bax} / \mathrm{Bcl}-2$ was decreased when $\mathrm{CsA}$ was combined with Cur treatment, compared with the CsA alone group, as demonstrated in Fig. $2 \mathrm{~B}$ and $\mathrm{C}$, which indicates that levels of the anti-apoptotic protein $\mathrm{Bcl}-2$ were higher compared with the proapoptotic protein Bax, thus indicating that Cur may improve cell survival in CsA-treated HK-2 cells.

Effect of Cur on CsA-induced CAN model in rats. To further evaluate the protective effect of Cur in a CsA-induced rat nephrotoxicity model, renal histopathological analysis was performed. Histopathological results are presented in Fig. 3. Hematoxylin and eosin staining demonstrated that the tissue 
A

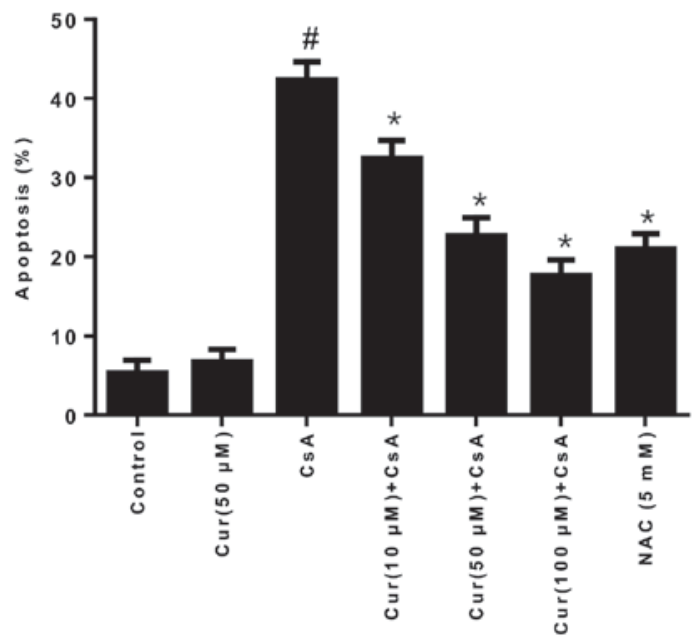

B

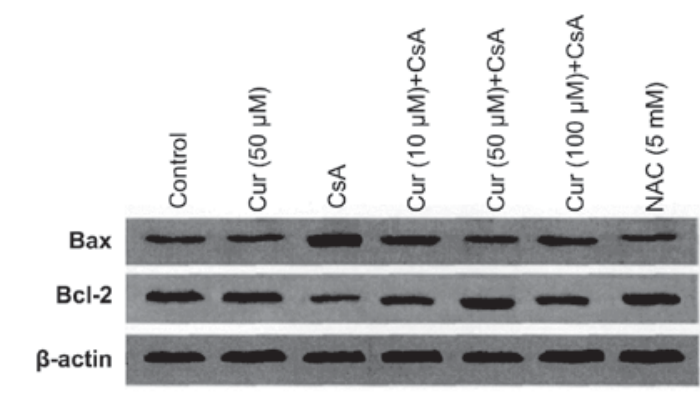

C

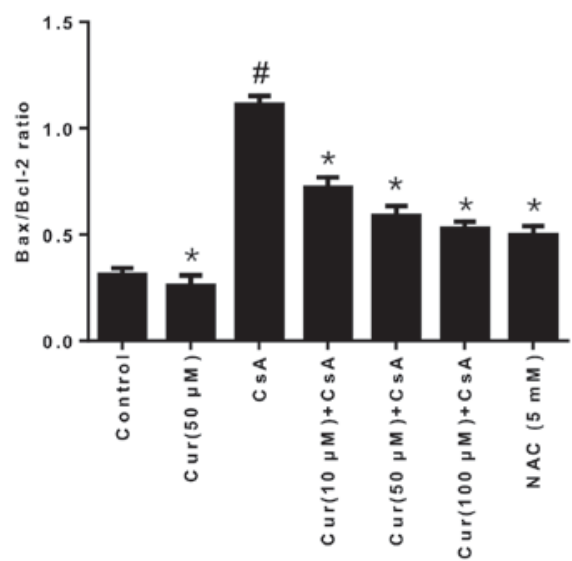

Figure 2. Effect of different concentrations of Cur on HK-2 cell apoptosis and the expression of apoptosis-associated proteins. (A) Effect of Cur on the apoptosis of HK-2 cells induced by CsA. (B) Effect of Cur on the protein expression of Bcl-2 and Bax in HK-2 cells. (C) Densitometric analysis was performed to determine the effect of Cur on the Bax/Bcl-2 ratio in HK-2 cells induced by $\mathrm{CsA} .{ }^{~} \mathrm{P}<0.05$ vs. control cells. ${ }^{*} \mathrm{P}<0.05$ vs. CsA only-treated cells. Cur, curcumin; CsA, cyclosporine A; Bax, Bcl-2-associated X; NAC, N-acetylcysteine.
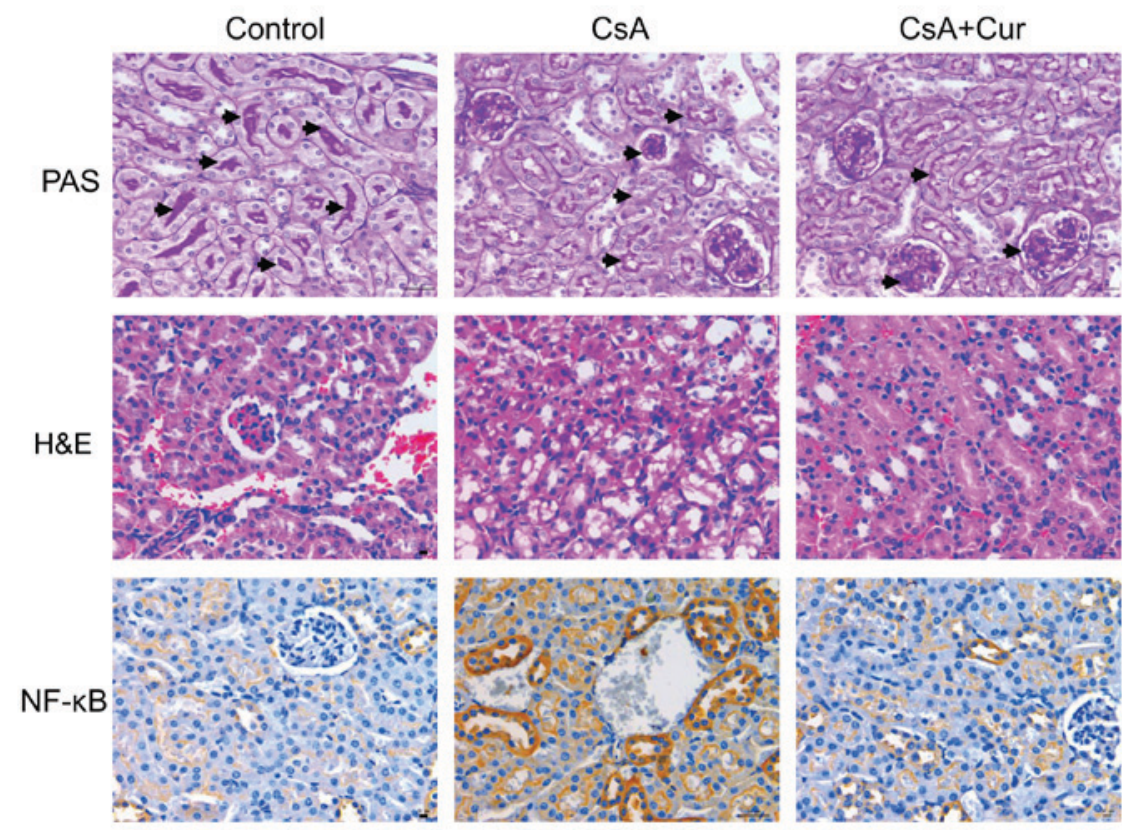

Figure 3. Effect of Cur on the CsA-induced CAN rat model. Renal PAS staining indicated that renal fibrosis was alleviated following administration of Cur in rats treated with CsA. Arrow, positive PAS staining. Renal H\&E staining indicated that renal structure was improved following administration of Cur in CsA-treated rats. Immunostaining of NF-kB indicated that Cur reduced the inflammatory response in CsA-treated rats. Scale bar, $30 \mu \mathrm{m}$. Cur, curcumin; CsA,

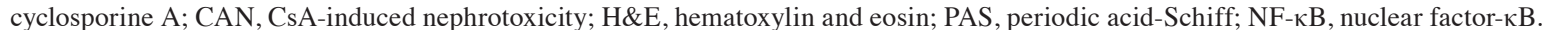

sections of the control group exhibited normal structure. By contrast, the kidneys of rats treated with CsA exhibited marked histological changes, cellular edema, vacuolar deformation and dissolution. These changes were reduced when CsA was combined with Cur treatment. The nucleus presented blue and the glomerular basement membrane was purple. The 
glomerular volume was markedly increased in the CsA group, with mesangial matrix hyperplasia (positive PAS staining), glomerular swelling, an irregular morphology of certain glomeruli, lobulated capillary loops and a markedly increased renal capsular space. NF- $\mathrm{NB}$-positive cell cytoplasm or nuclei were stained brown. The results demonstrated that NF- $\kappa \mathrm{B}$-positive cells, and therefore inflammation, were markedly increased in the CsA group compared with the control group, which was reduced when CsA was combined with Cur treatment.

Renal function in Cur-treated CAN rats. As demonstrated in Table I, renal failure was induced by continuous administration of CsA ( $20 \mathrm{mg} / \mathrm{kg} / \mathrm{day}$ ) for 21 days. The serum Crea and BUN were significantly elevated and the Ccr rate was significantly reduced $(\mathrm{P}<0.05)$ in the $\mathrm{CsA}$ alone group compared with the control group. Cur (30 mg/kg/day) alone did not significantly reduce renal function in rats compared with the control group, however, Cur significantly improved CsA-induced renal failure.

\section{Discussion}

CsA is a cyclic polypeptide composed of 11 amino acids. As a potent immunosuppressive agent, CsA specifically acts on lymphocytes and inhibits the synthesis and release of lymphokines, such as interleukin-2 (38). Quiescent lymphocytes are in the G0 phase of the cell cycle and the early G1 phase. Animal experiments have demonstrated that CsA extended the survival time of allogeneic organ transplantation and inhibited the cell-mediated immune response (39). CsA-induced dose-dependent renal toxicity is the primary reason for its limited clinical application, which results in renal tubular atrophy, vacuolar degeneration and renal failure (40). In the present study, rats were given CsA for 21 consecutive days, and the results demonstrated marked nephrotoxicity, with increased levels of Crea and BUN, reduced Ccr and marked vacuolar degeneration and tubular atrophy in the kidney. A previous study demonstrated that CsA-induced increases in ROS, leading to cell membrane lipid peroxidation, is one potential mechanism of CsA-induced nephrotoxicity, while another study reported that CsA induced in vivo inducible nitric oxide synthase expression, resulting in high concentrations of nitric oxide and ROS generation, and increased free radical activity (2). Peroxynitrite, a powerful free radical, has been reported to regulate the tricarboxylic acid cycle, mitochondrial function, electron transfer and affect DNA synthesis, resulting in increased pathological damage $(34,41)$. The results of the present study, from experiments on HK-2 cells, also confirmed that CsA treatment significantly increased the levels of MDA and Bax protein expression, and decreased SOD activity and Bcl-2 expression. Cur is an excellent hydrogen or neutron donor and, during redox reactions generated as a result of excessive free radicals, the body converts free radicals into phenolic oxygen free radicals, which protects the organism against free radical damage. In the body, Cur reacts with free radicals to generate more stable phenolic oxygen free radicals, thereby inactivating free radicals (27). In addition, Cur has been reported to exhibit a protective effect against CsA-induced nephrotoxicity in rats, as demonstrated by histological alterations and Glutathione S-transferase immune expression (42). Tirkey et al (42) reported that, through its antioxidant activity, Cur effectively salvaged CsA-induced nephrotoxicity. Furthermore, $\mathrm{Hu}$ et al (43) demonstrated that the protective effect of Cur may be mediated by inhibiting the hypermethylation of the klotho promoter. The present study confirmed that Cur significantly increased renal antioxidant capacity and decreased the $\mathrm{Bax} / \mathrm{Bcl}-2$ ratio in $\mathrm{Cs}$ A-treated HK-2 cells, which may be associated with the improvements in CsA-induced renal failure and renal tubular deformation and cell vacuolization following Cur treatment in rats. In addition, Tirkey et al (42) demonstrated that Cur markedly reduced elevated levels of thiobarbituric acid reactive substances, significantly attenuated renal dysfunction and increased the levels of antioxidant enzymes in CsA-treated rats and normalized the altered renal morphology. The development of renal diseases has been previously associated with $\mathrm{NF}-\kappa \mathrm{B}$ activation. $\mathrm{NF}-\kappa \mathrm{B}$ regulates the transcription of inflammatory factors in mesangial and tubular epithelial cells; therefore, it has a central role in the development and progression of renal disease (44). Wang et al (45) demonstrated that limb ischemic preconditioning-induced renoprotection in contrast-induced nephropathy may be dependent on increased renalase expression via activation of the tumor necrosis factor $\alpha / N F-\kappa B$ pathway. Renalase may contribute to the renal protective effect of delayed ischaemic preconditioning via the regulation of hypoxia-inducible factor- $1 \alpha(45,46)$. In conclusion, the present study demonstrated that Cur exhibited a protective effect on CsA-induced renal dysfunction, and the underlying mechanism may be associated with the antioxidant capacity of Cur in experimental animals. However, further investigation is required to determine whether Cur may be used as a clinical adjuvant to reduce renal toxicity induced by CsA.

\section{Acknowledgements}

This present study was funded by Ningbo Yinzhou Science and Technology Bureau Project [grant no. 2011 (111)].

\section{References}

1. Jorga A, Holt DW and Johnston A: Therapeutic drug monitoring of cyclosporine. Transplant Proc 36 (2 Suppl): 396S-403S, 2004.

2. Tedesco D and Haragsim L: Cyclosporine: A review. J Transplant 2012: 230386, 2012.

3. Zhong Z, Arteel GE, Connor HD, Yin M, Frankenberg MV, Stachlewitz RF, Raleigh JA, Mason RP and Thurman RG: Cyclosporin A increases hypoxia and free radical production in rat kidneys: Prevention by dietary glycine. Am J Physiol 275: F595-F604, 1998.

4. Pérez de Lema G, Arribas I, Prieto A, Parra T, de Arriba G, Rodríguez-Puyol D and Rodríguez-Puyol M: Cyclosporin A-induced hydrogen peroxide synthesis by cultured human mesangial cells is blocked by exogenous antioxidants. Life Sci 62: 1745-1753, 1998 .

5. Mariee AD and Abd-Ellah MF: Protective effect of docosahexaenoic acid against cyclosporine A-induced nephrotoxicity in rats: A possible mechanism of action. Ren Fail 33: 66-71, 2011.

6. Tavares P, Fontes Ribeiro CA and Teixeira F: Cyclosporin effect on noradrenaline release from the sympathetic nervous endings of rat aorta. Pharmacol Res 47: 27-33, 2003.

7. Wan Q and Liu ZY: Effect of curcumin on human umbillcal veln endothellal cell injury induced by lipocalin 2 . Chin $\mathrm{J}$ Arterioscler 21: 229-233, 2016 (In Chinese).

8. Djamali A, Reese S, Yracheta J, Oberley T, Hullett D and Becker B: Epithelial-to-mesenchymal transition and oxidative stress in chronic allograft nephropathy. Am J Transplant 5: 500-509, 2005. 
9. Shrestha BM and Haylor J: Biological pathways and potential targets for prevention and therapy of chronic allograft nephropathy. Biomed Res Int 2014: 482438, 2014.

10. Maryniak RK, First MR and Weiss MA: Transplant glomerulopathy: Evolution of morphologically distinct changes. Kidney Int 27: 799-806, 1985

11. Kang HM, Ahn SH, Choi P, Ko YA, Han SH, Chinga F, Park AS, Tao J, Sharma K, Pullman J, et al: Defective fatty acid oxidation in renal tubular epithelial cells has a key role in kidney fibrosis development. Nat Med 21: 37-46, 2015.

12. Fonseca I, Reguengo H, Almeida M, Dias L, Martins LS, Pedroso S, Santos J, Lobato L, Henriques AC and Mendonça D: Oxidative stress in kidney transplantation: Malondialdehyde is an early predictive marker of graft dysfunction. Transplantation 97: 1058-1065, 2014

13. Andersen JK: Oxidative stress in neurodegeneration: Cause or consequence? Nat Med 10 (Suppl): S18-S25, 2004.

14. Priya DK, Gayathri R, Gunassekaran GR and Sakthisekaran D Protective role of sulforaphane against oxidative stress mediated mitochondrial dysfunction induced by benzo(a)pyrene in female Swiss albino mice. Pulm Pharmacol Ther 24: 110-117, 2011.

15. Wei Y, Clark SE, Thyfault JP, Uptergrove GM, Li W, Whaley-Connell AT, Ferrario CM, Sowers JR and Ibdah JA: Oxidative stress-mediated mitochondrial dysfunction contributes to angiotensin II-induced nonalcoholic fatty liver disease in transgenic Ren2 rats. Am J Pathol 174: 1329-1337, 2009.

16. Evans JL, Goldfine ID, Maddux BA and Grodsky GM: Oxidative stress and stress-activated signaling pathways: A unifying hypothesis of type 2 diabetes. Endocr Rev 23: 599-622, 2002.

17. Yu JH and Kim H: Oxidative stress and inflammatory signaling in cerulein pancreatitis. World J Gastroenterol 20: 17324-17329, 2014.

18. Romero F, Herrera J, Nava M and Rodríguez-Iturbe B: Oxidative stress in renal transplantation with uneventful postoperative course. Transplant Proc 31: 2315-2316, 1999

19. Ruiz MC, Moreno JM, Ruiz N, Vargas F, Asensio C and Osuna A Effect of statin treatment on oxidative stress and renal function in renal transplantation. Transplant Proc 38: 2431-2433, 2006.

20. Vostálová J, Galandáková A, Svobodová AR, Kajabová M, Schneiderka P, Zapletalová J, Strebl P and Zadražil J: Stabilization of oxidative stress 1 year after kidney transplantation: Effect of calcineurin immunosuppressives. Ren Fail 34: 952-959, 2012

21. Nelson KM, Dahlin JL, Bisson J, Graham J, Pauli GF and Walters MA: The essential medicinal chemistry of curcumin. J Med Chem 60: 1620-1637, 2017.

22. Gupta SC, Patchva S, Koh W and Aggarwal BB: Discovery of curcumin, a component of golden spice, and its miraculous biological activities. Clin Exp Pharmacol Physiol 39: 283-299, 2012 .

23. Sharma M, Manoharlal R, Puri N and Prasad R: Antifungal curcumin induces reactive oxygen species and triggers an early apoptosis but prevents hyphae development by targeting the global repressor TUP1 in Candida albicans. Biosci Rep 30 391-404, 2010.

24. Rahmani AH, Al Zohairy MA, Aly SM and Khan MA: Curcumin: A potential candidate in prevention of cancer via modulation of molecular pathways. Biomed Res Int 2014: 761608, 2014.

25. Prakobwong S, Gupta SC, Kim JH, Sung B, Pinlaor P, Hiraku Y, Wongkham S, Sripa B, Pinlaor S and Aggarwal BB: Curcumin suppresses proliferation and induces apoptosis in human biliary cancer cells through modulation of multiple cell signaling pathways. Carcinogenesis 32: 1372-1380, 2011.

26. Fujisawa S, Atsumi T, Ishihara M and Kadoma Y: Cytotoxicity, ROS-generation activity and radical-scavenging activity of curcumin and related compounds. Anticancer Res 24: 563-569, 2004.

27. Calabrese V, Bates TE, Mancuso C, Cornelius C, Ventimiglia B, CambriaMT,DiRenzoL, De Lorenzo A and Dinkova-Kostova AT: Curcumin and the cellular stress response in free radical-related diseases. Mol Nutr Food Res 52: 1062-1073, 2008.

28. Trujillo J, Chirino YI, Molina-Jijón E, Andérica-Romero AC, Tapia E and Pedraza-Chaverrí J: Renoprotective effect of the antioxidant curcumin: Recent findings. Redox Biol 1: 448-456, 2013.
29. Pan Y, Wang Y, Cai L, Cai Y, Hu J, Yu C, Li J, Feng Z, Yang S, $\mathrm{Li} X$ and Liang G: Inhibition of high glucose-induced inflammatory response and macrophage infiltration by a novel curcumin derivative prevents renal injury in diabetic rats. Br J Pharmacol 166: 1169-1182, 2012.

30. Kim BH, Lee ES, Choi R, Nawaboot J, Lee MY, Lee EY, Kim HS and Chung $\mathrm{CH}$ : Protective effects of curcumin on renal oxidative stress and lipid metabolism in a rat model of type 2 diabetic nephropathy. Yonsei Med J 57: 664-673, 2016.

31. Pang XF, Zhang LH, Bai F, Wang NP, Garner RE, McKallip RJ and Zhao ZQ: Attenuation of myocardial fibrosis with curcumin is mediated by modulating expression of angiotensin II AT1/AT2 receptors and ACE2 in rats. Drug Des Devel Ther 9: 6043-6054, 2015.

32. Huang MT, Lysz T, Ferraro T, Abidi TF, Laskin JD and Conney AH: Inhibitory effects of curcumin on in vitro lipoxygenase and cyclooxygenase activities in mouse epidermis. Cancer Res 51: 813-819, 1991

33. Shen L and Ji HF: Insights into the inhibition of xanthine oxidase by curcumin. Bioorg Med Chem Lett 19: 5990-5993, 2009.

34. Ben P, Liu J, Lu C, Xu Y, Xin Y, Fu J, Huang H, Zhang Z, Gao Y, Luo L and Yin Z: Curcumin promotes degradation of inducible nitric oxide synthase and suppresses its enzyme activity in RAW 264.7 cells. Int Immunopharmacol 11: 179-186, 2011.

35. Tzankova V, Gorinova C, Kondeva-Burdina M, Simeonova R, Philipov S, Konstantinov S, Petrov P, Galabov D and Yoncheva K: Antioxidant response and biocompatibility of curcumin-loaded triblock copolymeric micelles. Toxicol Mech Methods 27: 72-80, 2017.

36. Sun YM, Zhang HY, Chen DZ and Liu CB: Theoretical elucidation on the antioxidant mechanism of curcumin: A DFT study. Org Lett 4: 2909-2911, 2002.

37. Hao CX, Su YJ, Wang QJ, et al: Inhibition effect of curcumin on AP-1 DNA binding activity increased in the kidney of experimental diabetic rats. J Med Pest Control 27: 417-418, 2011 (In Chinese)

38. Shin GT, Khanna A, Ding R, Sharma VK, Lagman M, Li B and Suthanthiran M: In vivo expression of transforming growth factor-beta1 in humans: Stimulation by cyclosporine. Transplantation 65: 313-318, 1998 .

39. Siemionow M, Ozer K, Izycki D, Unsal M and Klimczak A: A new method of bone marrow transplantation leads to extention of skin allograft survival. Transplant Proc 37: 2309-2314, 2005.

40. Sereno J, Rodrigues-Santos P, Vala H, Rocha-Pereira P, Alves R, Fernandes J, Santos-Silva A, Carvalho E, Teixeira F and Reis F: Transition from cyclosporine-induced renal dysfunction to nephrotoxicity in an in vivo rat model. Int J Mol Sci 15: 8979-8997, 2014.

41. Buffoli B, Pechánová O, Kojsová S, Andriantsitohaina R, Giugno L, Bianchi R and Rezzani R: Provinol prevents CsA-induced nephrotoxicity by reducing reactive oxygen species, iNOS, and NF-kB expression. J Histochem Cytochem 53: $1459-1468,2005$

42. Tirkey N, Kaur G, Vij G and Chopra K: Curcumin, a diferuloylmethane, attenuates cyclosporine-induced renal dysfunction and oxidative stress in rat kidneys. BMC Pharmacol 5: 15, 2005.

43. Hu Y, Mou L, Yang F, Tu H and Lin W: Curcumin attenuates cyclosporine A-induced renal fibrosis by inhibiting hypermethylation of the klotho promoter. Mol Med Rep 14: 3229-3236, 2016.

44. Zhang H and Sun SC: NF-кB in inflammation and renal diseases. Cell Biosci 5: 63, 2015.

45. Wang F, Yin J, Lu Z, Zhang G, Li J, Xing T, Zhuang S and Wang N: Limb ischemic preconditioning protects against contrast-induced nephropathy via renalase. EBioMedicine 9: 356-365, 2016.

46. Wang F, Zhang G, Xing T, Lu Z, Li J, Peng C, Liu G and Wang N: Renalase contributes to the renal protection of delayed ischaemic preconditioning via the regulation of hypoxia-inducible factor- $1 \alpha$. J Cell Mol Med 19: 1400-1409, 2015. 